\title{
Crude alkaloid extract of Rhazya stricta inhibits cell growth and sensitizes human lung cancer cells to cisplatin through induction of apoptosis
}

\author{
Ayman I. Elkady \\ Department of Biological Sciences, Faculty of Sciences, King Abdulaziz University, Jeddah, \\ Kingdom of Saudi Arabia.
}

\begin{abstract}
There is an urgent need to improve the clinical management of non-small cell lung cancer (NSCLC), one of the most frequent causes of cancer-related deaths in men and women worldwide. Rhazya stricta, an important medicinal plant used in traditional Oriental medicine, possesses anti-oxidant, anti-carcinogenic and free radical scavenging properties. This study was done to explore the potential anticancer activity of a crude alkaloid extract of $R$. stricta (CAERS) against the NSCLC line A549. CAERS markedly suppressed the growth of A549 cells and considerably enhanced the anti-proliferative potential of cisplatin. CAERS-mediated inhibition of A549 cell growth correlated with the induction of apoptosis that was accompanied by numerous morphological changes, DNA fragmentation, an increase in the $\mathrm{Bax} / \mathrm{Bcl}-2$ ratio, the release of mitochondrial cytochrome $c$, activation of caspases 3 and 9 and cleavage of poly(ADP-ribose)-polymerase. CAERS reduced the constitutive expression of anti-apoptotic proteins (Bcl-2, Bcl- $\mathrm{X}_{\mathrm{L}}$, Mcl-1 and Survivin) and cell cycle regulating proteins (cyclin D1 and c-Myc), but enhanced expression of the proapoptotic proteins Noxa and BAD. These observations indicate that CAERS induced apoptosis and sensitized NSCLC to cisplatin via a mitochondria-mediated apoptotic pathway. These data provide a rationale for using a combination of CAERS and CDDP to treat NSCLC and other CDDP-resistant tumors.
\end{abstract}

Keywords: apoptosis, lung cancer, medicinal plant, RT-PCR, western blot.

Received: June 13, 2012; Accepted: September 28, 2012.

\section{Introduction}

Lung cancer is one of the most common cancers in many countries and accounts for $28 \%$ of all cancer-related deaths (Bilello et al., 2002; Jemal et al., 2008). Clinically, lung cancer is classified into two groups, namely, small cell and non-small cell lung cancer (NSCLC). The latter is more prevalent, accounting for almost $85 \%$ of lung cancers (Jemal et al., 2004). Although early detection and treatment can improve the prognosis, only $15 \%$ of patients with NSCLC are diagnosed at an early stage since most lung cancer begins to grow silently without any symptoms until the cancer is in an advanced stage (Gargiullo et al., 2002; Beadsmoore and Screaton, 2003; Jemal et al., 2004), at which point the treatment options are generally limited to surgery or radiation. Currently, the most active chemotherapeutic agent for the treatment of NSCLC is cisplatin (cis-diamminedichloroplatinum(II); CDDP) and CDDPbased combinations have remained the standard first-line chemotherapy for advanced NSCLC for more than two decades (Johnson, 2000; Wang et al., 2004). Unfortunately, despite its great efficacy, CDDP is associated with several

Send correspondence to Ayman I. Elkady. Zoology Department, Faculty of Science, Alexandria University, Alexandria, Egypt. E-mail: aielkady@yahoo.co.uk. major problems, including a number of side effects and the development of resistance that tend to limit the therapeutic potential of CDDP (Rom et al., 2000; Gridelli et al., 2003; Wang et al., 2004). Consequently, new approaches such as novel effective drugs with low toxicities or excellent combination regimens are needed to overcome CDDP-resistance in NSCLC therapy.

During the past decade, various studies have shown that current cancer therapies (for example, chemotherapy, $\gamma$-irradiation, immunotherapy or suicide gene therapy) exert their antitumor effect primarily by triggering apoptosis in cancer cells (Makin and Dive, 2001). Consistent with this evidence, most tumor cells, including NSCLC, are naturally resistant to apoptotic-related cell death and to nonapoptotic cell death such as necrosis, autophagy, senescence, mitotic catastrophe and paraptosis (Okada and Mak, 2004; Debatin and Krammer, 2004). To date, three apoptotic pathways have been identified, i.e., mitochondrial-, death receptor- and endoplasmic reticulum stress-mediated apoptosis (reviewed in Wong, 2011). Of these, the mitochondrial pathway initiates apoptosis in most physiological and pathological situations. A variety of stimuli such as stress and drugs induce disruption of the mitochondrial membrane and the release of mitochondrial proteins such as cytochrome $c$ (cyt $c$ ). 
The release of cyt $c$ from mitochondria is tightly regulated by Bcl-2 family proteins that include anti-apoptotic (e.g., Bcl-2) and pro-apoptotic (e.g., Bax) members (Reed, 2000; Wong, 2011). Bcl-2 can stabilize mitochondrial permeability to prevent the release of cyt $c$ whereas Bax increases the membrane permeability leading to the release of cyt $c$ from mitochondria (Reed, 2000; Wong, 2011). Upon release from mitochondria into the cytosol, cyt $c$, together with Apaf-1, activates caspase-9 and the latter then activates caspases 3 and 7 (Cruchten and Den Broeck, 2002; Wong, 2011). Subsequently, active caspase-3 cleaves downstream substrates such as poly-(ADPribose) polymerase (PARP), which are responsible for the morphological and biochemical changes that are the hallmarks of apoptosis (Cruchten and Den Broeck, 2002; Wong, 2011). However, tumor cells do not undergo apoptosis easily because of defects in their ability to activate the death signaling pathway. Consequently, one effective strategy for the treatment/prevention of cancer is to search for agents that can activate apoptotic pathways in tumor cells (Call et al., 2008; Liu et al., 2011).

Members of the plant family Apocynaceae have been used in folk medicine for centuries and many of their constituents have been isolated and are now in clinical use, e.g., vinblastine, vincristine and reserpine (Neuss, 1970). Rhazya stricta (harmal) is an important medicinal species of the Apocynaceae used in indigenous medicinal herbal drugs to cure various diseases in southern Asia (Pakistan, India and Afghanistan) and the Middle East (Saudi Arabia, Qatar, United Arab Emirates, Iran and Iraq) (Gilani et al., 2007). Indeed, extracts of $R$. stricta leaves are prescribed in folklore medicine for the treatment of various disorders such as diabetes, sore throat, helminthesis, inflammatory conditions and rheumatism (Ali et al., 2000, 1995, 1998). Some of the chemical constituents of $R$. stricta and their pharmacological activities have been reviewed (Ali et al., 2000). The plant extract contains many alkaloids, glycosides, flavonoids, tannins and triterpenes (Ahmed et al., 1983; Al-Yahya et al., 1990). The effective uses of $R$. stricta described in traditional medicine have been attributed to the presence of indole alkaloids. Indeed, activity-guided phytochemical analysis of $R$. stricta extract has shown that the alkaloidal fraction has the highest biological activity (Tanira et al., 2000). In addition, two indole alkaloids, 16-epi-Z-isositsirikine and didemethoxycarbonyltetrahydrosecamine, isolated from $R$. stricta have antineoplastic activity (Mukhopadhayay et al., 1981, 1983; Attaur-Rahman and Zaman, 1986).

Previously work has shown that an aqueous extract of $R$. stricta, acting as a single agent, inhibits cell proliferation in the breast cancer cell lines MCF-7 and MDA MB-231 (Baeshen et al., 2012). In contrast, no detailed studies have addressed the effect of a crude alkaloid extract of $R$. stricta (CAERS) on cancers. The present study was undertaken to assess the impact of CAERS on the growth of NSCLC
A549 cells and to examine the mechanism of action. The results described here clearly show that CAERS suppressed the growth of A564 cells and increased the sensitivity to and cytotoxicity of CDDP. CAERS sensitized A549 cells to CDDP through a mitochondria-dependent apoptotic pathway. These data provide a basis for using a combination of CAERS and CDDP to treat lung carcinoma and other tumors.

\section{Materials and Methods}

\section{Preparation of crude alkaloid extract from $R$. stricta}

A crude alkaloid extract of $R$. stricta leaves was prepared essentially as described elsewhere (Tanira et al., 2000), with some modifications. Briefly, air-dried leaves of R. stricta $(350 \mathrm{~g})$ were soaked in $80 \%$ methanol ( $1 \mathrm{~L})$ at ambient temperature for seven days after which the methanolic extract was evaporated in a rotatory evaporator and the remaining residue was suspended in water and filtered. The aqueous extract was then acidified with $10 \%$ glacial acetic acid and extracted with chloroform. This chloroform fraction contained weakly basic alkaloids and neutral compounds. The remaining aqueous solution was alkalinized using $\mathrm{NaOH}$ and the $\mathrm{pH}$ was adjusted to 11 . The alkaline aqueous layer was extracted with chloroform to yield a chloroform fraction enriched in strongly basic alkaloids (Tanira et al., 2000). The chloroform layer was evaporated to dryness and the resulting residue was re-dissolved in DMSO to the desired concentrations.

\section{Cell culture}

The human NSCLC cell line A549 and non-malignant human foreskin fibroblasts (HF-5 cells) were obtained from King Fahd Center for Medical Research, King Abdulaziz University, Saudi Arabia. The A549 cells were maintained in Dulbecco's modified Eagle's medium (DMEM, Promega) supplemented with 10\% of FBS (Promega) and $1 \%$ penicillin-streptomycin antibiotics (Promega) and were grown at $37{ }^{\circ} \mathrm{C}$ in a humidified atmosphere with $5 \% \mathrm{CO}_{2}$.

\section{Cell growth assay}

Cell viability and the effects of drugs on the growth of NSCLC cells were assessed with the trypan blue dye exclusion assay. Briefly, A549 cells were seeded onto 24-well plates $\left(50 \times 10^{3}\right.$ cells/well $)$ and grown overnight. The cells were then treated with increasing concentrations of CAERS $(0,3,6,15,30,45$ and $60 \mu \mathrm{g} / \mathrm{mL})$ or $\operatorname{CDDP}(0,5$, $10,25,50,75$ and $100 \mu \mathrm{g} / \mathrm{mL}$ ) and incubated for 24,48 or $72 \mathrm{~h}$. At the end of each incubation, the floating and adherent cells were collected (with care being taken that none of the floating cells were lost during washes) and pelleted by centrifugation ( $700 \mathrm{~g}, 5 \mathrm{~min})$. The cells were re-suspended in $25 \mu \mathrm{L}$ of phosphate-buffered saline (PBS), mixed with $5 \mu \mathrm{L}$ of $0.4 \%$ trypan blue solution and counted using a hemocytometer under an inverted microscope. Cell growth 
rates were determined by counting the number of viable cells in each CAERS-/CDDP-treated well and expressing this as a percentage of the total number of viable cells in the control well (no drugs added).

\section{Clonogenic assay}

The clonogenic assay was done by seeding 1000 cells/well onto 6-well plates. After incubation for $24 \mathrm{~h}$, the cells were treated with increasing concentrations of CAERS $(0,3,6,15,30,45$ and $60 \mu \mathrm{g} / \mathrm{mL})$ for $72 \mathrm{~h}$ and then washed twice with PBS to remove any remaining CAERS before adding fresh medium. The cells were subsequently incubated for another 12 days after which the colonies were stained the $0.4 \%$ trypan blue solution. Colonies with $>50$ cells were scored as surviving and the percentage survival was determined using the equation: percentage of survival $=($ colonies with drug treatment $/$ colonies without drug treatment, i.e., control) x 100.

\section{Assessment of cell morphological changes}

Cells were seeded $\left(50 \times 10^{3} /\right.$ well) onto 24 -well plates and treated for $24 \mathrm{~h}$ with increasing concentrations $(0,3,6$, $15,30,45$ and $60 \mu \mathrm{g} / \mathrm{mL}$ ) of CAERS after which they were washed in PBS and fixed and permeabilized in 3.7\% paraformaldehyde (Sigma) in PBS for $10 \mathrm{~min}$ at room temperature. Fixed cells were washed with PBS and stained with ethidium bromide solution $(20 \mu \mathrm{g} / \mathrm{mL})$ for $20 \mathrm{~min}$ at room temperature. The cells were washed twice more with PBS and analyzed. Representative images were captured with an inverted fluorescence microscope (Carl Zeiss, Germany) using the magnification indicated in the figures.

\section{DNA fragmentation assay}

Cells were seeded ( $20 \times 10^{4} /$ well) onto 6 -well plates and treated for $24 \mathrm{~h}$ with different concentrations $(0,3,6$, 15 and $30 \mu \mathrm{g} / \mathrm{mL}$ ) of CAERS after which the cells were harvested, washed in PBS and purified using a DNA purification kit (DNeasy Blood and Tissue kit, QIAGEN), according to the manufacturer's recommendations. The concentration of DNA was determined spectrophotometrically and DNA was electrophoresed on a $1 \%$ agarose gel at $100 \mathrm{~V}$ for $2 \mathrm{~h}$ and analyzed. The gel was stained with ethidium bromide $(0.5 \mu \mathrm{g} / \mathrm{mL})$ and DNA was visualized with a UV trans-illuminator (Bio-Rad).

\section{RNA extraction and reverse transcriptase-PCR}

Cells were seeded ( $20 \times 10^{4} /$ well) onto 6 -well plates and treated with different concentrations $(0,3,6,15$ and $30 \mu \mathrm{g} / \mathrm{mL}$ ) of CAERS for $24 \mathrm{~h}$. After this period, floating and adherent cells were collected (with care being taken that none of the floating cells were lost during washes) and pelleted by centrifugation $(700 \mathrm{~g}, 5 \mathrm{~min})$. RNA extraction and reverse transcriptase-PCR were done as previously described (Elkady, 2012). Briefly, total RNA was extracted, reverse transcribed and amplified by PCR using QIAamp RNA Blood mini kits (QIAGEN) according to the manufacturer's instructions. The polymerase chain reaction (PCR) was done using gene-specific primers. The primer sequences for Bcl-2, Bcl- $\mathrm{x}_{\mathrm{L}}, \mathrm{Mcl}-1$, survivin (BIRC5), Bad, Noxa, c-Myc, cyclin D1 and HPRT1 were described earlier (El-Kady et al., 2011). Amplification products obtained by PCR were separated electrophoretically on $1 \%$ agarose gels and visualized by ethidium bromide $(0.5 \mu \mathrm{g} / \mathrm{mL})$ staining (Elkady, 2012).

\section{Preparation of mitochondrial and cytosolic extracts}

To detect cyt $c$ release by western immunoblotting, mitochondrial and cytosolic extracts were obtained as described previously (Elkady, 2012). Briefly, cells were seeded $\left(20 \times 10^{4} /\right.$ well) onto 6 -well plates, treated with the indicated concentrations of CAERS and CDDP and incubated for $24 \mathrm{~h}$. After this incubation, the cells were collected by centrifugation, washed twice with cold PBS, resuspended in $500 \mu \mathrm{L}$ of ice-cold cytosol extraction buffer (20 mM HEPES, pH 7.5, $10 \mathrm{mM} \mathrm{KCl,} 1.5 \mathrm{mM} \mathrm{MgCl}_{2}$, $1 \mathrm{mM}$ EDTA and $1 \mathrm{mM}$ EGTA) containing a protease inhibitor cocktail (1 mM PMSF, $1 \%$ aprotinin, $1 \mathrm{mM}$ leupeptin and $1 \mu \mathrm{g}$ of pepstatin $\mathrm{A} / \mathrm{mL}$ ). After a 30 min incubation on ice, the cells were homogenized in the same buffer using a dounce homogenizer (30 strokes) and centrifuged $\left(1000 \times \mathrm{g}, 10 \mathrm{~min}, 4^{\circ} \mathrm{C}\right)$. The supernatant was collected and centrifuged again $(14,000 \times \mathrm{x}, 30 \mathrm{~min})$ to collect the mitochondria-rich (pellet) and cytosolic (supernatant) fractions. The supernatant was used as cytosolic lysate while the pellet was suspended in lysis buffer $(137 \mathrm{mM} \mathrm{NaCl}, 20 \mathrm{mM}$ Tris, pH 7.9, $10 \mathrm{mM} \mathrm{NaF,} 5$ mM EDTA, 1 mM EGTA, 10\% (v/v) glycerol and $1 \%$ Triton X-100) supplemented with a protease inhibitor cocktail (Protease Inhibitor Cocktail Set III, Calbiochem) before being centrifuged to obtain the mitochondrial lysate. Proteins concentrations were determined with a BCA protein assay kit (Pierce) and equal amounts of protein fractions were subjected for further analyses as described below.

\section{Western blot analysis}

After treatment with CAERS and CDDP, the cells were harvested, washed three times with PBS and lysed in cold lysis buffer containing $0.05 \mathrm{mM}$ Tris- $\mathrm{HCl}, 0.15 \mathrm{mM}$ $\mathrm{NaCl}, 1 \mathrm{M}$ EGTA, $1 \mathrm{M}$ EDTA, $20 \mathrm{mM} \mathrm{NaF}, 100 \mathrm{mM}$ $\mathrm{Na}_{3} \mathrm{VO}_{4}, 0.5 \%$ NP40, $1 \%$ Triton X-100 and $0.5 \mathrm{mM}$ phenylmethylsulfonyl fluoride, $\mathrm{pH} 7.4$, with freshly added protease inhibitor cocktail (Protease Inhibitor Cocktail Set III, Calbiochem). The amount of protein was quantified using a BCA protein assay kit (Pierce). Western immunoblotting was done essentially as described elsewhere (Elkady, 2012). Briefly, equal amounts ( $20 \mu \mathrm{g}$ per treatment) of protein from control and CAERS/CDDP-treated cells were boiled for $5 \mathrm{~min}$ in Laemmli buffer and separated by SDSPAGE on $10 \%$ polyacrylamide gels. The proteins were sub- 
sequently transferred to PVDF membranes that were then blocked and probed with primary antibodies (Spring Bioscience) against the desired proteins followed by incubation with secondary HRP-conjugated antibodies (Spring Bioscience). In all experiments, the blots were stripped with stripping buffer (62.5 mM Tris, pH 6.7, 2\% SDS and $90 \mathrm{mM} 2$-mercaptoethanol) and reprobed with anti- $\beta$-actin (Spring Bioscience) antibody as a control for protein loading. Signals were detected with an enhanced chemiluminescence detection kit (Amersham).

\section{Statistical analysis}

All assays were done at least three times and the results were expressed as the mean \pm SD unless otherwise stated. Statistical comparisons were done by using Student's $t$-test. Probability values of $\mathrm{p}<0.05$ indicated statistical significance.

\section{Results}

\section{CAERS suppresses cell growth and colony} formation and sensitizes A549 cells to CDDP

Initially, the effect of CAERS on the death of A549 cells was evaluated by trypan blue dye exclusion, with the viability being expressed as a percentage of that of untreated (control) cells (assumed to be 100\%). Figure 1 shows that continuous exposure to increasing concentrations of CAERS $(0,3,6,15,30,45$ and $60 \mu \mathrm{g} / \mathrm{mL})$ for 24 , 48 and $72 \mathrm{~h}$ resulted in a concentration- and time-dependent decrease in cell viability relative to control cultures. The $\mathrm{IC}_{50}$ (inhibitory concentration 50\%) for CAERS-induced cell death was $\sim 28,15$ and $8 \mu \mathrm{g}$ at 24,48 and $72 \mathrm{~h}$, respectively. To assess whether CAERS-dependent growth inhibition was selective for cancer cells, the effect of CAERS on the viability of non-malignant human foreskin fibroblasts (HF-5 cells) was also assessed. Figure 1B shows that HF-5 cells were significantly more resistant to growth inhibition by CAERS than were A549 cells. The strongest effect was seen at the highest concentration of CAERS, where the survival of HF-5 cells was inhibited by only $\sim 15 \%$ after $72 \mathrm{~h}$, indicating that CAERS in not toxic to normal, non-transformed cells. These results suggest that CAERS may selectively target A549 cancer cells but spare normal fibroblasts, which is a highly desirable property of potential anticancer agents.

CDDP is one of the most effective chemotherapeutic drugs for treating NSCLC but it has a narrow therapeutic window between efficacy and unacceptable toxicity (Rom et al., 2000; Gridelli et al., 2003). Since CAERS effectively inhibited the growth of A549 cells and had little effect on the growth of normal HF-5 fibroblasts, the ability of CAERS to enhance the cell killing effect of CDDP was examined. For this, the effect of CDDP alone or in combination with CAERS on the growth of A549 cells was assessed. Figure $1 \mathrm{C}$ shows the effect of increasing concen- trations $(0,5,10,25,50,75$ and $100 \mu \mathrm{g} / \mathrm{mL})$ of CDDP alone on $\mathrm{A} 549$ cells; the $\mathrm{IC}_{50}$ values were 70,60 and $40 \mu \mathrm{g} / \mathrm{mL}$ at 24,48 and $72 \mathrm{~h}$, respectively. On the other hand, combined treatment with CAERS $(6 \mu \mathrm{g} / \mathrm{mL})$ and increasing concentrations of CDDP markedly increased the inhibition of A549 cell growth by CDDP. In this case, there was a decrease in the $\mathrm{IC}_{50}$ values of CDDP to 15,8 and $4 \mu \mathrm{g} / \mathrm{mL}$ at 24, 48 and $72 \mathrm{~h}$, respectively, in the presence of CAERS (Figure 1D). Pair-wise comparisons between the $\mathrm{IC}_{50}$ values shown in panels $\mathrm{C}$ and $\mathrm{D}$ showed that, in general, CDDP alone had an approximately half-maximal inhibitory effect on cell growth at all concentrations over 24, 48 and $72 \mathrm{~h}$. These results indicate that CAERS strongly enhances the inhibition of cell proliferation by CDDP in the human NSCLC A549 cell line.

Subsequently, a clonogenic assay was done to confirm the potential of CAERS to suppress the growth of A549 cells. As shown in Figure 1E, the clonogenic survival of A549 cells was significantly affected by exposure to CAERS for $72 \mathrm{~h}$, with CAERS causing a concentrationdependent decrease in the number and size of growing colonies when compared to the untreated controls $(100 \%)$. These results demonstrate that CAERS had a cytostatic effect on long-term colony formation by A549 cells.

\section{CAERS induces apoptosis in A549 cells}

The major goal of cancer chemotherapy is to commit tumor cells to apoptosis following exposure to anticancer agents, and it is generally believed that the induction of apoptosis is the primary cytotoxic mechanism of phytochemicals (Khan et al., 2007). To determine whether CAERS inhibited the cell growth of A549 cells by inducing apoptosis and whether CAERS-induced apoptosis accounts for its ability to enhance CDDP-induced inhibition of cell growth and proliferation, cells were treated with increasing concentrations of CAERS for $24 \mathrm{~h}$ and frequency of apoptotic cell death was assessed by phase microscopy. As seen under an inverted phase microscope (Figure 2A), untreated A549 cells grew well to form confluent monolayers with a homogenous morphology containing lightly and evenly stained nuclei. In contrast, CAERS-treated cells showed marked morphological changes compared to untreated cells. Most of the cells treated with CAERS concentrations $\geq 30 \mu \mathrm{g} / \mathrm{mL}$ had densely stained nuclear granular bodies containing highly condensed chromatin ('apoptotic bodies'). The nuclear changes and apoptotic body formation characteristic of apoptosis were visualized by incubating A549 cells with CAERS for $24 \mathrm{~h}$ followed by staining with ethidium bromide (Figure 2B).

DNA fragmentation to yield DNA ladders is a characteristic feature of apoptosis (Nagata, 2000). To examine whether CAERS might provoke such fragmentation in A549 cells, genomic DNA from A549 cells treated with CAERS was extracted and separated by agarose gel electrophoresis. Figure $2 \mathrm{C}$ shows that there were clear DNA 

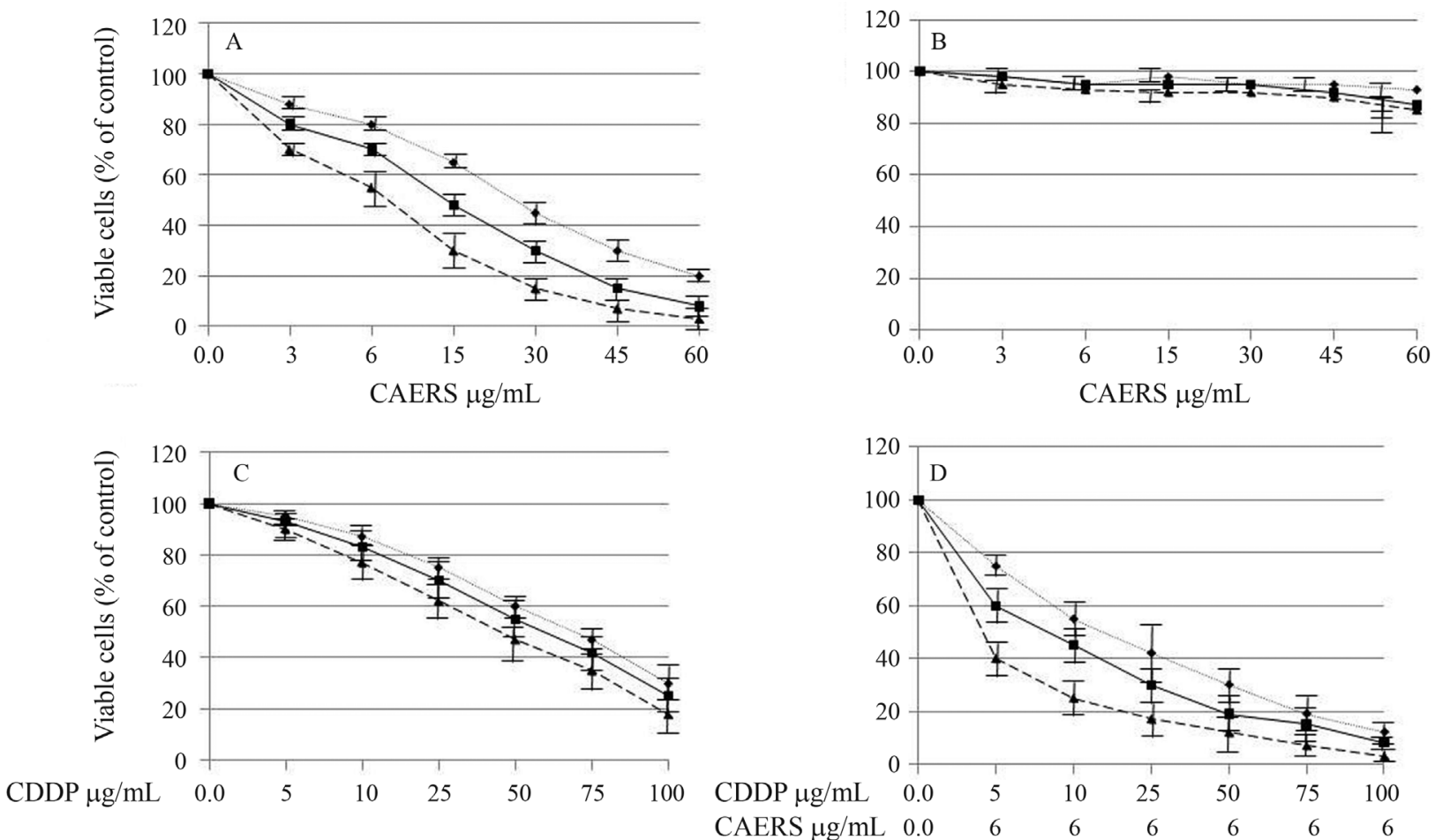

E

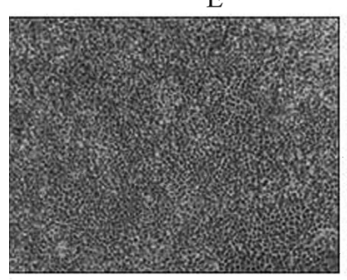

CAERS $\mu \mathrm{g} / \mathrm{mL}$

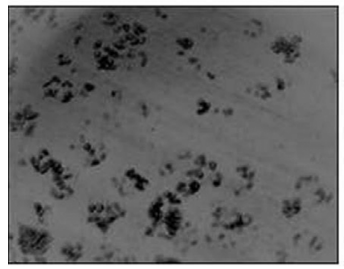

CAERS $\mu \mathrm{g} / \mathrm{mL}$

45
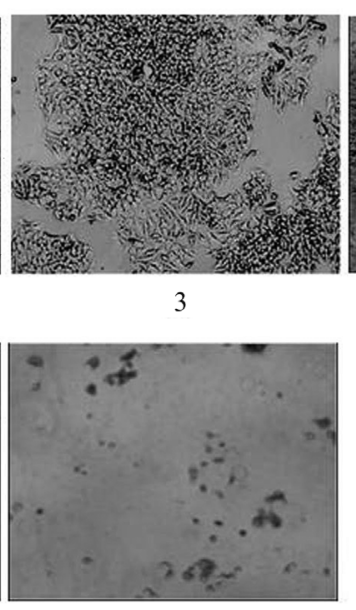

60

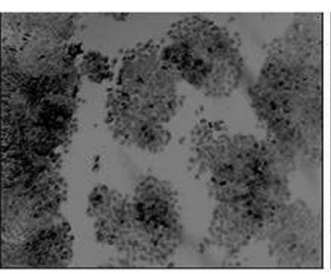

6

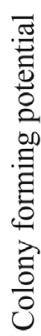

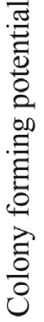

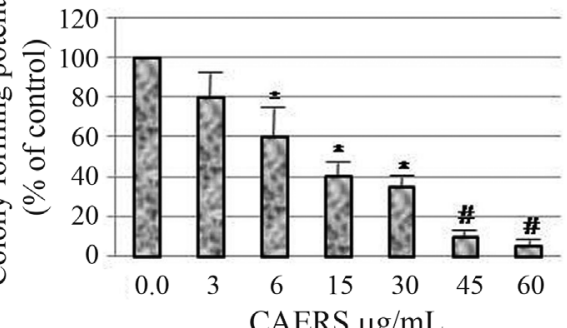

Figure 1 - CAERS suppresses cell growth and colony formation and sensitizes A549 cells to CDDP. A549 (A) and HF-5 (B) cells (50 x $10^{3}$ cells/well) were seeded onto 24-well plates and treated with the indicated concentrations of CAERS alone for $24 \mathrm{~h}$ (dotted line), $48 \mathrm{~h}$ (solid line) and $72 \mathrm{~h}$ (dashed line). (B and C) A549 cells (50 x $10^{3}$ cells/well) were seeded onto 24-well plates and treated with the indicated concentrations of CDDP alone (C) or CDDP + CAERS (D) for 24, 48 and $72 \mathrm{~h}$. The inhibition of cell proliferation was assessed by the trypan blue dye exclusion assay. Cell viability was expressed as a percentage of control (no drug treatment) cell viability. The points are the mean \pm SD of at least three independent experiments. (E) Effects of CAERS on clonogenicity of A549 cells. Cells were seeded onto a 6-well plate at 1000 cells/well and treated with the indicated concentrations of CAERS as detailed in Materials and Methods. The colonies were counted under a dissection microscope. A survival of $100 \%$ corresponded to the number of colonies obtained with cells that were not treated with CAERS. The experiment was repeated three times and the colony forming potential of the cells at each concentration of CAERS is expressed as a percent of the control and is reported as the mean $\pm \mathrm{SD}$. ${ }^{*} \mathrm{p}<0.05$ and ${ }^{\#} \mathrm{p}<0.001$ compared to control cells $(100 \%)$.

fragmentation ladders in samples from cells treated with all concentrations of CAERS. The comet assay was used to confirm DNA fragmentation after incubation with CAERS. This assay is a sensitive method for monitoring single strand (ss) DNA breaks at the single cell level (reviewed in
Tice et al., 2000). When A549 cells were treated with 3, 6 and $15 \mu \mathrm{g}$ of CAERS/mL for $24 \mathrm{~h}$ there was significant ssDNA damage, as indicated by the increased tail length in the CAERS-treated cells compared with the controls (data not shown). Thus, these two independent methods of as- 
A

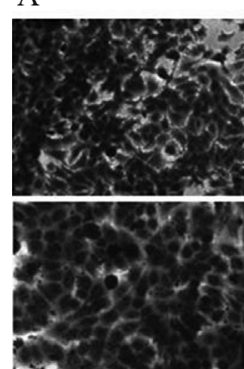

CAERS $\mu \mathrm{g} / \mathrm{mL} \quad 0.0$

B

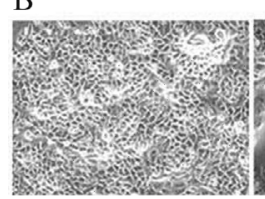

CAERS $\mu \mathrm{g} / \mathrm{mL} \quad 0.0$

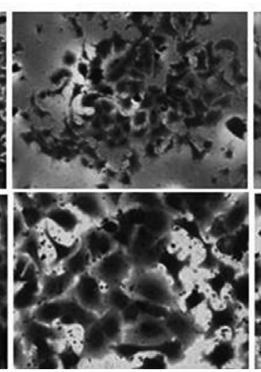

3

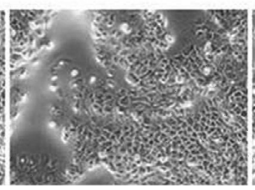

3

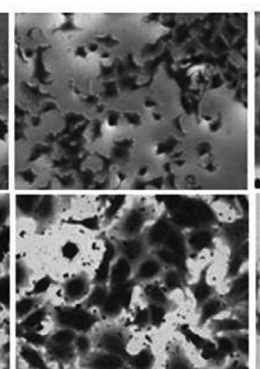

6

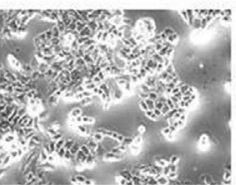

6

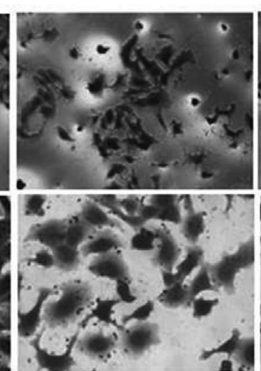

15

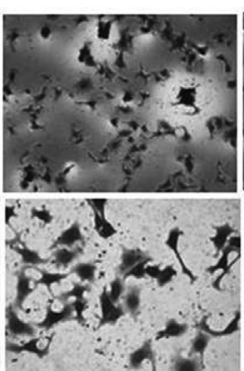

30

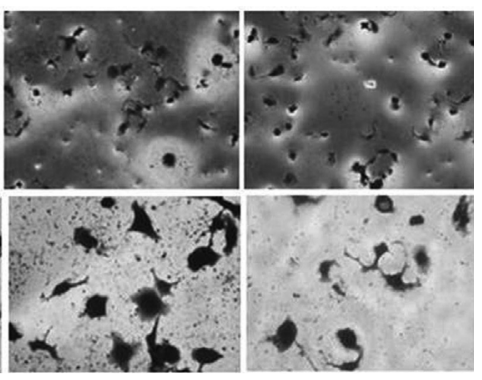

45

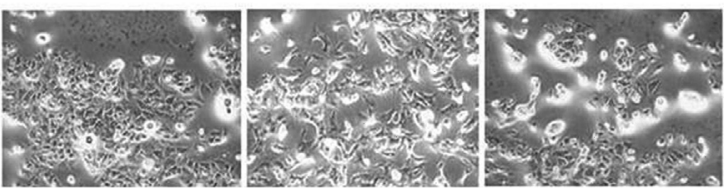

15

30

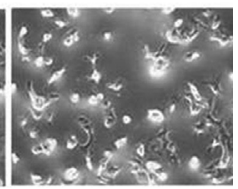

60

C

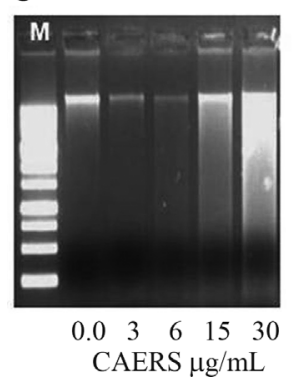

Figure 2 - CAERS induces apoptosis in A549 cells. (A) Morphological changes in A549 cells after incubation with CAERS. (A) The cells were treated with the indicated concentrations of CAERS for $24 \mathrm{~h}$ after which they were examined using an inverted microscope (first row: magnification - 200x; second row: magnification - 400x). (B) The cells were stained with ethidium bromide for 20 min and photographed with a fluorescence microscope using a red filter (magnification: 200x). (C) Fragmentation of DNA isolated from A549 cells incubated with CAERS. The cells were incubated with the indicated concentrations of CAERS for $24 \mathrm{~h}$ after which DNA fragmentation was assessed as described in Materials and Methods. Lane 'M' indicates the DNA marker ladder. The data are representative of three independent experiments with similar results.

sessing apoptosis provided similar results, suggesting that the anti-proliferative potential of CAERS was linked to its ability to induce apoptosis in A549 cells.

\section{CAERS modulates the expression of apoptotic regulatory proteins and their activation in A549 cells}

To elucidate how CAERS induced A549 cell apoptosis, changes in the expression of several key apoptosisrelated proteins, including Bcl-2, Bax, cyt $c$, caspases 9 and 3 , and poly(ADPribose) polymerase (PARP) were examined. Bcl-2 and Bax play critical roles in the regulation of cyt $c$ release from the mitochondria into the cytosol; the released cyt $c$ initiates caspase activation and apoptotic cell death. PARP is an early marker of chemotherapy-induced apoptosis (Reed, 2000; Cruchten and Den Broeck, 2002; Wong, 2011). A549 cells were treated with increasing concentrations of CAERS for $24 \mathrm{~h}$ after which the levels of Bcl-2, Bax, cyt $c$, caspases 9 and 3, and cleaved PARP were analyzed by western blotting. Figure 3 shows that incubation with CAERS significantly reduced the level of Bcl-2 and increased those of Bax (A) and cytosolic cyt $c$ (B), as well as the activation of caspases 9 and 3 and cleavage of PARP (C). These results demonstrate that CAERS induced A549 cell apoptosis at the molecular level, possibly by activating an intrinsic apoptotic pathway.

\section{CAERS modulates the expression of antiapoptotic- and cell cycle-regulating genes in A549 cells}

To assess the significance of the expression patterns of antiapoptotic and cell cycle regulating genes in response to CAERS, A549 cells were treated with CAERS for $24 \mathrm{~h}$ and then possible alterations in the mRNA expression levels of various apoptosis-/cell cycle-related genes were analyzed by RT-PCR using gene-specific primers. The proteins examined included the anti-apoptotic proteins Bcl-2, Bcl- $X_{\mathrm{L}}$ and Mcl-1, a member of the IAP family of proteins, Survivin (Reed, 2000) and the cell cycle-regulating proteins cyclin D1 and c-Myc (Liao et al., 2007). In addition, the expression levels of the proapoptotic $\mathrm{BH} 3$-only protein, Noxa (Reed, 2000; Wong, 2011), and a positive regulator of cell death, Bad (Danial, 2009), were also examined. Figure 4 shows that incubation with CAERS consistently mod- 
A

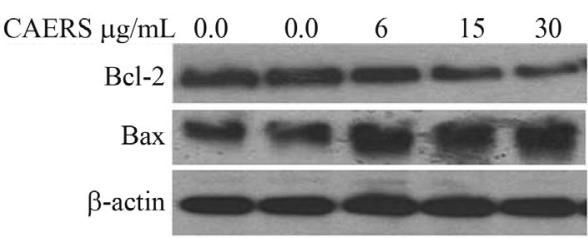

B

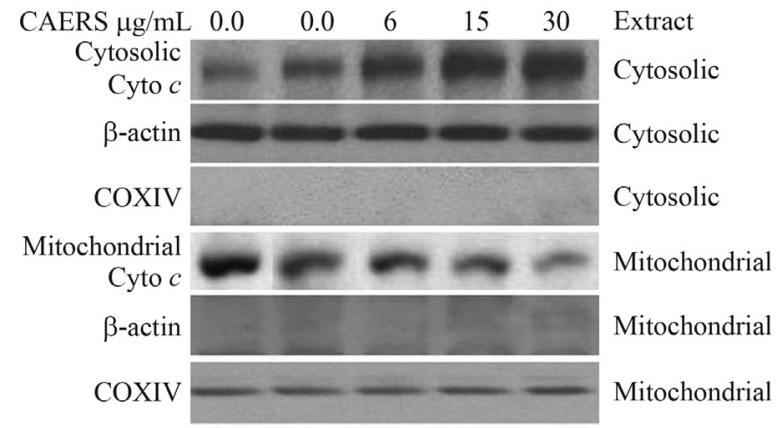

$\mathrm{C}$

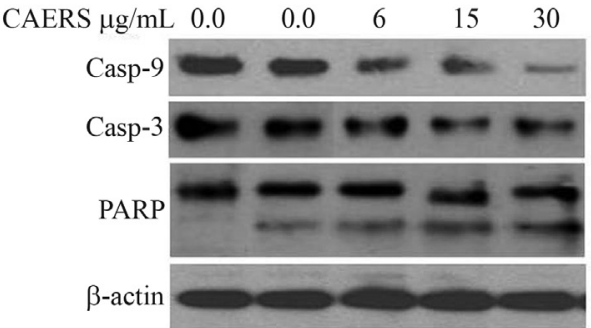

Figure 3 - CAERS modulates expression of apoptosis regulatory proteins and their activation in A549 cells. A549 cells $\left(20 \times 10^{4}\right.$ cells/well) were seeded onto 6-well plates and treated with the indicated concentrations of CAERS for $24 \mathrm{~h}$. Subsequently, $20 \mu \mathrm{g}$ of cell extract protein isolated from CAERS-treated A549 cells was subjected to SDS-PAGE in $10 \%$ polyacrylamide gels, transferred to PVDF membranes and immunoblotted with antibodies against the proteins of interest. Treatment with CAERS increased the $\mathrm{Bax} / \mathrm{Bcl}-2$ ratio (A), promoted mitochondrial cyto $c$ release (B) and activated caspases 9 and 3 and PARP cleavage (C). The immunoblots of cyto $c$ (B) were stripped and re-probed with anti-cytochrome oxidase IV (COXIV) to confirm the purity of the cytoplasmic fraction and equal loading of the mitochondrial fraction. In all experiments, the membranes were stripped and re-probed with anti- $\beta$-actin antibody as a loading control. The data are representative of three separate experiments.

ulated the expression of this panel of genes in a concentration-dependent manner. Thus, CAERS down-regulated the expression of Bcl-2, Bcl- $\mathrm{X}_{\mathrm{L}}$, Mcl-1, Survivin, c-Myc and cyclin D1, but enhanced that of Bad and Noxa. These data suggest that CAERS induced apoptosis in A549 cells by selectively inhibiting anti-apoptotic gene expression and upregulating Bad and Noxa expression.

\section{Discussion}

Lung cancer is the most frequent cause of cancerrelated deaths in men and women worldwide, with NSCLC accounting for $75-80 \%$ of lung cancers (Bilello et al., 2002; Jemal et al., 2008). CDDP-based combination treatments

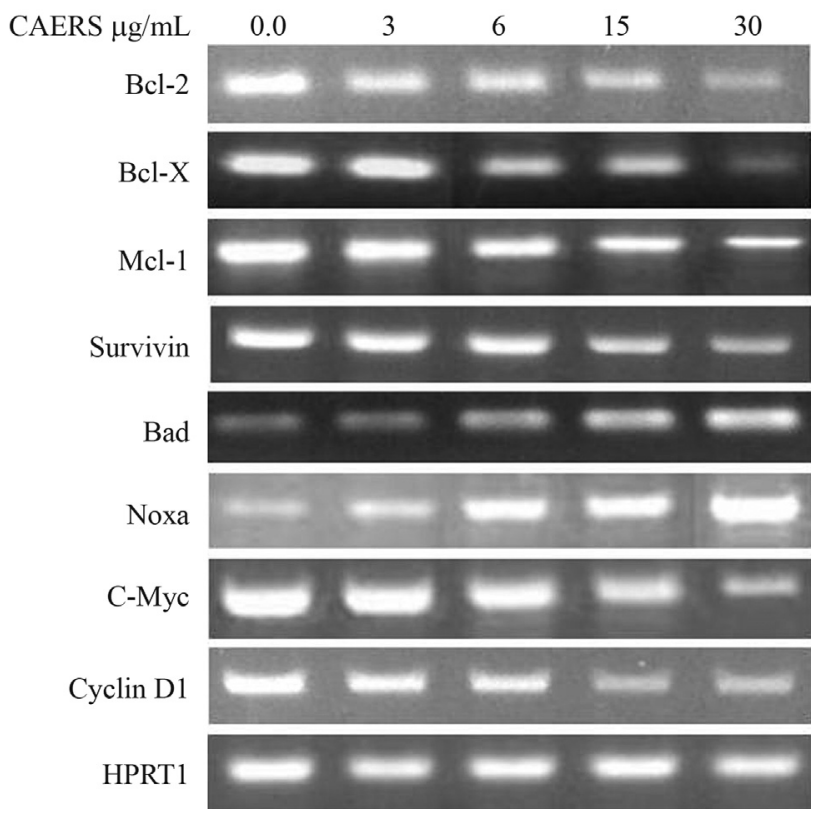

Figure 4 - CAERS modulates the expression of antiapoptotic and cell cycle -regulated gene products in A549 cells. A549 cells ( $20 \times 10^{4}$ cells/well) were seeded onto 6-well plates and treated with the indicated concentrations of CAERS for $24 \mathrm{~h}$. Total RNA was then isolated, reverse transcribed and subjected to PCR with gene-specific primers. The PCR products of the genes were then subjected to electrophoresis in $1 \%$ agarose gels and visualized by staining with ethidium bromide. HPRT1 was used as the internal control. A typical result from three independent experiments is shown.

are the first-line chemotherapy for NSCLC (Johnson, 2000; Wang et al., 2004). However, since current CDDP-based chemotherapy has a narrow therapeutic window between efficacy and unacceptable toxicity (Johnson, 2000; Ramalingam and Belani, 2004), there is an urgent need to develop low toxicity chemotherapeutics for NSCLC to reduce treatment failure. Recent work has shown that an aqueous extract of $R$. stricta successfully inhibited the proliferation and induced apoptotic cell death in breast cancer cell lines (Baeshen et al., 2012). The present study was done to investigate whether CAERS, an aqueous extract of $R$. stricta, could inhibit A549 cell growth and enhance the cytotoxicity of CDDP; the mechanism of CAERS action was also examined.

The results described here show that CAERS significantly suppressed the growth of human A549 cells in a time- and concentration-dependent manner. Furthermore, cytotoxicity assays indicated that CDDP and CAERS acted synergistically to suppress the growth of A549 cells. In contrast, CAERS had no significant effect on non-malignant human fibroblasts (HF-5 cells), which raises the possibility that CAERS may selectively target lung cancer cells. However, the experiments described here cannot exclude the possibility of tissue-specific differences between human fibroblasts and lung cells. Additional cytotoxicity studies using a normal lung cell line and different lung cancer cell lines, as well as studies in vivo in nude mice are nec- 
essary to prove that CAERS can inhibit tumor growth without major side effects. Further proof of the growthsuppressing potential of CAERS was provided by the colony formation assay which showed a significant reduction in the number and size of colonies in CAERS-treated cells compared with untreated control cells. Collectively, these data indicate that CAERS could be a promising candidate for restricting the growth of lung cancer cells.

The ability of CAERS to induce cell death in A549 cells was examined in detail in order to elucidate the mechanism by which CAERS markedly enhanced the CDDPinduced inhibition of NSCLC cell growth. The inhibitory activity of CAERS on cell growth was related to the induction of apoptosis since CAERS-treated A549 cells exhibited the typical morphological features of apoptosis (Cruchten and Den Broeck, 2002), such as a loss of cell viability, cell shrinkage, irregularity in cell shape, and cell detachment. In addition, staining with ethidium bromide revealed nuclear condensation, DNA fragmentation and perinuclear apoptotic bodies in CAERS-treated cells. Furthermore, DNA laddering and the comet assay (data not shown) demonstrated that CAERS induced apoptosis in A549 cells and augmented the apoptotic potential of CDDP in A549 cells. Since CDDP can trigger cancer cell death by inducing apoptosis (Sorenson et al., 1990; Wang et al., 2000; Del Bello et al., 2001) it is possible that CAERS enhances the effect of CDDP on A549 cell proliferation partly by augmenting the ability of CDDP to initiate apoptosis.

Most anticancer agents induce DNA damage by interacting with DNA either directly or indirectly; the latter route may involve secondary stress-response signaling pathways that trigger apoptosis by activating the intrinsic (mitochondrial) apoptotic pathway and, in some cases, simultaneously activating the extrinsic (death receptor) pathway (Green, 2000). A variety of stimuli such as stress and drugs induce perturbation of the mitochondrial membrane and the release of mitochondrial proteins, such as cyt $c$, leading to the initiation of apoptotic cascades (Green, 2000). However, the mitochondria-dependent pathway for apoptosis is governed by Bcl-2 family proteins; the proteins Bax and Bcl-2 have opposing roles in initiating mitochondrial apoptotic events and modulating apoptosis (Wong, 2011). Bcl-2 is associated with the outer mitochondrial membrane where it plays a pivotal and overriding protective role by preserving mitochondrial structure and function, thereby preventing the onset of a mitochondrial permeability transition and inhibiting the release of cyt $c$ to the cytosol. In contrast, Bax, a dominant-negative inhibitor of Bcl-2, induces a mitochondrial permeability transition and promotes apoptosis (Wong, 2011). Thus, when the level of Bax increases, the mitochondrial membrane becomes permeable to cyt $c$.

Upon its release into cytosol, cyt $c$, together with Apaf-1, activates caspase-9 that then activates caspase-3 (Reed, 2000; Wong, 2011). Active caspase-3 cleaves the
$116 \mathrm{kDa}$ PARP protein to an $89 \mathrm{kDa}$ fragment, which is a characteristic marker of the execution of apoptosis (Reed, 2000; Cruchten and Den Broeck, 2002). The findings described here fit the above scenarios perfectly since CAERS significantly enhanced cytosolic cyt $c$ that was associated with a concomitant decrease in the level of mitochondrial cyt $c$, suggesting that this treatment resulted in the release of cyt $c$ from the mitochondrion into the cytosol. In addition, CAERS enhanced the activation of caspase-9, implying that CAERS mediated A549 cell growth via the caspase-9 apoptotic pathway, in agreement with previous studies showing that the caspase-9-dependent mitochondria-mediated apoptotic pathway is the primary pathway for antitumor agent-induced apoptosis (Khan et al., 2007). Furthermore, western blotting demonstrated downregulation of $\mathrm{Bcl}-2$ expression and up-regulation of Bax expression.

Based on these observations, it is tempting to speculate that treatment with CAERS resulted in cyt $c$ release and the activation of caspase- 9 and caspase- 3 partly via the disruption of a balance between Bax and Bcl-2. Subsequently, active caspase- 3 mediated the cleavage of PARP to account for DNA fragmentation as well as other morphological and biochemical changes during apoptosis (Cruchten and Den Broeck, 2002). CAERS therefore appears to exert its antiproliferative potentiality on A549 cell growth via the intrinsic apoptosis pathway involving Bcl-2 family proteins and caspase-9 activation. The down-regulation of Bcl-2 and up-regulation of Bax by CAERS corroborates published reports indicating that the ratio of anti-apoptotic Bcl-2 to pro-apoptotic Bax protein at least partly determines the susceptibility of the cell to a death signal (Vander Heiden and Thompson, 1999) and can be used as a predictive marker for therapeutic response to therapy (Mackey et al., 1998). The down-regulation of Bcl-2 by CAERS highlights the potential usefulness of CAERS as an ideal therapeutic agent for treating NSCLC.

RT-PCR showed that CAERS down-regulated the expression of genes known to have a pro-survival role, such as Bclx $_{\mathrm{L}}$, Mcl-1 and Survivin (Reed, 2000). For example, Bclx $_{\mathrm{L}}$ and Mcl-1 suppress the release of cyt $c$ from mitochondria and prevent apoptosis (Reed, 2000; Liu et al., 2001) and overexpression of Mcl-1 delayed apoptosis induced by growth factor withdrawal and other cytotoxic agents (Liu et al., 2001). Survivin is selectively expressed in most human neoplasms, including NSCLC, and is associated with a poor prognosis in patients with NSCLC (Zhang et al., 2012); Survivin also confers tumor cell resistance to anticancer agents and ionizing radiation (Pennati et al., 2007). Recent findings suggest that Survivin and Bcl-2 are up-regulated in NSCLC tissues and may act synergistically in the development, invasion and metastasis of NSCLC (Gao et al., 2012). In addition, CAERS downregulated the mRNA levels of c-Myc and cyclin D1. The $\mathrm{c}-\mathrm{Myc}$ oncoprotein promotes cell cycling progression, 
plays a vital role in most human cancers (Dang et al., 2006) and cooperates with Mcl-1 in the development of NSCLC (Allen et al., 2011). Similarly, cyclin D1 is a central player in the cell cycle and plays an essential role in the development of NSCLC (Ai et al., 2012). Consequently, the down-regulation of Bcl-2, Bclx $\mathrm{L}_{\mathrm{L}}, \mathrm{Mcl}-1$, Survivin, c-Myc and cyclin D1 by CAERS imply that this extract could effectively target the survival advantage provided by these effectors. However, it remains unclear whether the downregulation of mRNA expression by CAERS was due to transcriptional down-regulation, mRNA stabilization or both. On the other hand, CAERS up-regulated the expression of genes involved in counteracting cell survival, such as Bad and Noxa. Down- and up-regulation of Mcl-1 and Noxa expression, respectively, by CAERS is important since studies of molecular targeted therapies have shown that ABT-737, a Bad mimetic, binds with high affinity to BCL-X $\mathrm{X}_{\mathrm{L}}$ BCL-2 and BCL-w but not to Mcl-1 (Labi et al., 2008). Hence, therapy with ABT-737 would be ineffective in cells expressing significant amounts of Mcl-1 (van Delft et al., 2006; Huang and Sinicrope, 2008). This would be critical, particularly in tumor cells such as NSCLC that have a high expression of Mcl-1 (Luo et al., 2011) since only Noxa, but not other BH3-only family members, appears to be crucial in fine-tuning cell death decisions by targeting the Mcl-1 for proteasomal degradation (Ploner et al., 2009). Consequently, the down-regulation of Mcl-1 and up-regulation of Noxa by CAERS may tip the balance of events towards apoptosis in A549 cells.

In summary, the results described above have shown that a natural plant-derived antitumor agent (CAERS) inhibits growth and potentiates the anticancer activity of the cytotoxic drug CDDP in human A549 cells. CAERS inhibited A549 cell growth via apoptotic mechanisms. The induction of apoptosis by CAERS was mediated by regulation of the levels and activities of apoptosis regulatory proteins. Together, these findings provide a scientific basis for using a combination of CAERS and CDDP as a potentially effective chemotherapy regimen for treating patients with resistant lung cancer, although further preclinical investigations are warranted. The ability of CAERS to improve the antitumor effects of CDDP in A549 orthotopic xenografts is currently being studied.

\section{Acknowledgments}

The author thanks the Deanship of Scientific Research (DSR), King Abdulaziz University, Jeddah, Saudi Arabia for technical and financial support of this research.

\section{References}

Ahmad Y, Fatima K, Le Quesne PPW and Atta-ur-Rahman (1983) Further alkaloidal constituents of the leaves of Rhazya stricta. Phytochemistry 22:1017-1019.

Ai T, Wang Z, Zhang M, Zhang L, Wang N, Li W and Song L (2012) Expression and prognostic relevance of STAT3 and cyclin D1 in non-small cell lung cancer. Int J Biol Markers 27:132-138.

Ali BH, Bashir AK, Banna NR and Tanira MO (1995) Central nervous system activity of Rhazya stricta Dence in mice. Clin Exp Pharmacol Physiol 22:248-253.

Ali BH, Bashir AK and Tanira MO (1998) The effect of Rhazya stricta, a traditional medicinal plant, on the forced swimming test in rats. Pharmacol Biochem Behav 59:547-550.

Ali BH, Al-Qarawi AA, Bashir AK and Tanira MO (2000) Phytochemistry, pharmacology and toxicity of Rhazya stricta Decne: A review. Phytother Res 14:229-234.

Allen TD, Zhu CQ, Jones KD, Yanagawa N, Tsao MS and Bishop JM (2011) Interaction between MYC and MCL1 in the genesis and outcome of non-small-cell lung cancer. Cancer Res 71:2212-2221.

Al-Yahya MA, Al-Meshal IA, Mossa JS, Al-Badr AA and Tariq M (1990) Saudi Plants: A Phytochemical and Biochemical Approach. King Saud University Press, Riyadh, pp 123-129.

Atta-ur-Rahman and Zaman K (1986) 1,2-Dehydroaspidospermidine N-oxide, an alkaloid from Rhazya stricta. Phytochemistry 25:1779-1780.

Baeshen NA, Elkady AI, Abuzinadah OA and Mutwakil MH (2012) Potential anticancer activity of medicinal herb, Rhazya stricta, against human breast cancer. Afr J Biotechnol 11:8960-8972.

Beadsmoore CJ and Screaton NJ (2003) Classification, staging and prognosis of lung cancer. Eur J Radiol 45:8-17.

Bilello KS, Murin S and Matthay RA (2002) Epidemiology, etiology, and prevention of lung cancer. Clin Chest Med 23:1-25.

Call JA, Eckhardt SG and Camidge DR (2008) Targeted manipulation of apoptosis in cancer treatment. Lancet Oncol 9:1002-1011.

Cruchten SV and Den Broeck WV (2002) Morphological and biochemical aspects of apoptosis, oncosis and necrosis. Anat Histol Embryol 31:214-223.

Dang CV, O'Donnell KA, Zeller I, Nguyen T, Osthus RC and Li F (2006) The c-Myc target gene network. Semin Cancer Biol $16: 253-326$

Danial NN (2009) BAD: Undertaker by night, candyman by day. Oncogene 27:S53-S70.

Debatin KM and Krammer PH (2004) Death receptors in chemotherapy and cancer. Oncogene 23:2950-2966.

Del Bello B, Valentini MA, Zunino F, Comporti M and Maellaro E (2001) Cleavage of Bcl-2 in oxidant- and cisplatininduced apoptosis of human melanoma cells. Oncogene 20:4591-4595.

Elkady AI (2012) Crude extract of Nigella sativa inhibits proliferation and induces apoptosis in human cervical carcinoma HeLa cells. Afr J Biotechnol 11:12710-12720.

El-Kady AI, Sun Y, Li Y-X and Lia DJ (2011) Cyclin D1 inhibits whereas c-Myc enhances the cytotoxicity of cisplatin in mouse pancreatic cancer cells via regulation of several members of the NF- $\kappa \mathrm{B}$ and $\mathrm{Bcl}-2$ families. J Carcinog 10:24.

Gao Q, Yang S and Kang MQ (2012) Influence of survivin and Bcl-2 expression on the biological behavior of non-small cell lung cancer. Mol Med Rep 5:1409-1414.

Gargiullo P, Wingo PA, Coates RJ and Thompson TD (2002) Recent trends in mortality rates for four major cancers, by sex and race/ethnicity - United States. Morb Mortal Wkly Rep 51:49-53. 
Gilani SA, Kikuchi A, Shinwari ZK, Khattak ZI and Watanabe KN (2007) Phytochemical, pharmacological and ethnobotanical studies of Rhazya stricta Decne. Phytother Res 21:301-307.

Green DR (2000) Apoptotic pathways: Paper wraps stone blunts scissors. Cell 102:1-4.

Gridelli C, Rossi A and Maione P (2003) Treatment of non-small cell lung cancer: State of the art and development of new biologic agents. Oncogene 22:6629-6638.

Huang S and Sinicrope FA (2008) BH3 mimetic ABT-737 potentiates TRAIL-mediated apoptotic signaling by unsequestering Bim and Bak in human pancreatic cancer cells. Cancer Res 68:2944-2951.

Jemal A, Tiwari RC, Murray T, Ghafoor A, Samuels A, Ward E, Feuer EJ and Thun MJ (2004) Cancer statistics. CA Cancer J Clin 54:8-29.

Jemal A, Seigal R, Ward E, Hao Y, Xu J, Murray T and Thun M (2008) Cancer statistics. CA Cancer J Clin 58:71-96.

Johnson DH (2000) Evolution of cisplatin-based chemotherapy in non-small cell lung cancer: A historical perspective and the Eastern Cooperative Oncology Group experience. Chest 117:S133-S137.

Khan N, Afaq F and Mukhtar H (2007) Apoptosis by dietary factors: The suicide solution for delaying cancer growth. Carcinogenesis 28:233-239.

Labi V, Grespi F, Baumgartner F and Villunger A (2008) Targeting the $\mathrm{Bcl}-2$-regulated apoptosis pathway by $\mathrm{BH} 3$ mimetics: A breakthrough in anticancer therapy? Cell Death Differ 15:977-987.

Liao D, Thakur A, Wu J, Biliran H and Sarkar F (2007) Perspectives on c-Myc, cyclin D1, and their interaction in cancer formation, progression, and response to chemotherapy. Crit Rev Oncog 13:93-158.

Liu H, Perlman H, Pagliari LJ and Pope RM (2001) Constitutively activated Akt-1 is vital for the survival of human monocytedifferentiated macrophages. Role of Mcl-1, independent of

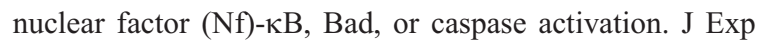
Med 194:2113-2126.

Liu JJ, Lin M, Yu JY, Liu B and Bao JK (2011) Targeting apoptotic and autophagic pathways for cancer therapeutics. Cancer Lett 300:105-114.

Luo L, Zhang T, Liu H, Lv T, Yuan D, Yao Y, Lv Y and Song Y (2011) MiR-101 and Mcl-1 in non-small-cell lung cancer: Expression profile and clinical significance. Med Oncol 29:1681-1686.

Mackey TJ, Borkowski A, Amin P, Jacobs SC and Kyprianou N (1998) Bcl-2/Bax ratio as a predictive marker for therapeutic response to radiotherapy in patients with prostate cancer. Urology 52:1085-1090.

Makin G and Dive C (2001) Apoptosis and cancer chemotherapy. Trends Cell Biol 11:S22-S26.

Mukhopadhayay S, Handy GA, Funayama S and Cordell GA (1981) Anticancer indole alkaloids of Rhazya stricta. J Nat Prod 44:696-700.

Mukhopadhayay S, El-Sayed A, Handy GA and Cordell GA (1983) Catharanthus alkaloids XXXVII. 16-Epi-isositsirikine, a monomeric indole alkaloid with antineoplastic activity from Catharanthus roseus and Rhazya stricta. J Nat Prod 46:409-413.

Nagata S (2000) Apoptotic DNA fragmentation. Exp Cell Res 256:12-18.

Neuss N (1970) Indole alkaloids. In: Pelletier SW (ed) Chemistry of the Alkaloids. Van Nostrand Reinhold, New York, pp 213-266.

Okada H and Mak TW (2004) Pathways of apoptotic and nonapoptotic death in tumour cells. Nat Rev Cancer 4:592-603.

Pennati M, Folini M and Zaffaroni N (2007) Targeting survivin in cancer therapy: Fulfilled promises and open questions. Carcinogenesis 28:1133-1139.

Ploner C, Kofler R and Villunger A (2009) Noxa: At the tip of the balance between life and death. Oncogene 27:S84-S92.

Ramalingam S and Belani CP (2004) State-of-the-art chemotherapy for advanced non-small cell lung cancer. Semin Oncol 31:S68-S74.

Reed JC (2000) Mechanisms of apoptosis. Am J Pathol 157:1415-1426.

Rom WN, Hay JG, Lee TC, Jiang Y and Tchou-Wong KM (2000) Molecular and genetic aspects of lung cancer. Am J Respir Crit Care Med 161:1355-1367.

Sorenson CM, Barry MA and Eastman A (1990) Analysis of events associated with cell cycle arrest at G2 phase and cell death induced by cisplatin. J Natl Cancer Inst 82:749-755.

Tanira MO, Ali BH, Bashir AK, Dhanasekaran S, Tibricia EM and Elves LM (2000) Mechanism of the hypotensive activity of the alkaloidal fraction of Rhazya stricta. Pharmacol Res 41:369-378.

Tice RR, Agurell E, Anderson D, Burlinson B, Hartmann B, Kobayashi H, Miyamae Y, Rojas Y, Ryu J-C and Sasaki YF (2000) Single cell gel/Comet assay: Guidelines for in vitro and in vivo genetic toxicology testing. Environ Mol Mutagen 35:206-221.

van Delft MF, Wei AH, Mason KD, Vandenberg CJ, Chen L, Czabotar PE, Willis SN, Scott CL, Day CL, Cory S, et al. (2006) The BH3 mimetic ABT-737 targets selective Bcl-2 proteins and efficiently induces apoptosis via $\mathrm{Bak} / \mathrm{Bax}$ if Mcl-1 is neutralized. Cancer Cell 10:389-399.

Vander Heiden MG and Thompson CB (1999) Bcl-2 proteins: Regulators of apoptosis or of mitochondrial homeostasis? Nat Cell Biol 1:E209-E216.

Wang G, Reed E and Li QQ (2004) Molecular basis of cellular response to cisplatin chemotherapy in non-small cell lung cancer (Review). Oncol Rep 12:955-65.

Wang X, Martindale JL and Holbrook NJ (2000) Requirement for ERK activation in cisplatin-induced apoptosis. J Biol Chem 275:39435-39443.

Wong RSY (2011) Apoptosis in cancer: From pathogenesis to treatment. Wong J Exp Clin Cancer Res 30:87.

Zhang LQ, Wang J, Jiang F, Xu L, Liu FY and Yin R (2012) Prognostic value of survivin in patients with non-small cell lung carcinoma: A systematic review with meta-analysis. PLoS One 7:e34100.

Associate Editor: Anamaria Aranha Camargo

License information: This is an open-access article distributed under the terms of the Creative Commons Attribution License, which permits unrestricted use, distribution, and reproduction in any medium, provided the original work is properly cited 